than lupoid. In the case of cancerous or sarcomatous ulceration, the destruction of the soft parts can be regulated and determined very accurately. Unlike the escharotics in common use, it has practically no effect on healthy cutaneous or mucous surfaces, but requires the action of a gramulating or raw surface to determine the formation of sulphurous and sulphuric acids, which are apparently the agents which influence the vitality of the organisms and tissues with which they come in contact. I have also found sulphur most useful in the foul ulcerative stomatitis which is so common among the children of the poor, and which resists so obstinately such local treatment as is usually adopted. In such cases, if gauze or wool be dusted abundantly with the finely powdered drug, and this be retained in firm contact with the foul ulcerated surface for an hour or two, sufficient destruction results to clear the surface of its infective organisms, and it then heals rapidly. Should one application not produce a sufficient result, a second or even more may be required, the number depending on the extent and locality of the ulceration, the facility with which the plug can be retained in position, \&c. Also in the foul impetiginoug alcers in children, the application of sulphur is similarly most effectual in the destruction of the microorganisms producing those conditions. I might multiply very largely similar examples of the good results that may be obtained by the action of sulphur used in this manner, but I think that I have given enough to induce other surgeons to give it a good trial. Sulphur, like iodoform, becomes active as a germicide, and is very considerably more powerful in its action than iodoform only when in immediate contact with a raw surface, the living tissues causing it to form certain combinations with hydrogen and oxygen. ${ }^{3}$

St. Thomag's-street, S. E.

HYDATID OF LIVER; OPERATION ; RECOVERY. BY ROBERT JONES, F.R.C.S. EDIN.,

HONORARY SURGEON, ROYAL SOCTHERN HOSPITAL, LIVERPOOL.

THE patient, a woman aged twenty-one, was sent to me by Dr. Evans of Festiniog through Dr. Carter, who had diagnosed hydatid of liver. I first saw her on May 8th, 1893. She then gave the following history. About six months previously she noticed 3 swelling below the lower border of the ribs on the right side. It caused no pain or inconvenience, and seemed to her about the size of a hen's egg. The tumour developed rapidly, but she was able to go on with her work, paying but little attention to it. She took her food well, and up to five weeks before my examination of her she was in absolutely good health and suffered no local disturbance. She then had rheumatic fever, from which she made a rapid recovery. Her family history was good. It should be noted that three dogs were kept where she was a servant, two of them living in the house.

On examination the patient looked healthy, with rosy cheeks and bright eyes. The abdominal swelling was dull on

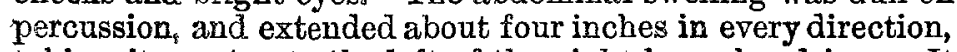
taking its centre to the left of the right hypochondrium. It was uniform in contour and moved up and down during respiration, the skin not being affected beyond being tense. The mass conveyed a thrill to the hand on palpation, but was non-pulsatile and no bruit could be heard on auscultation.

I transferred her for operation into the Royal Southern Hospital. An incision was made on May 17th in the middle line of the abdomen about three inches in length, from about one inch and a half below the ensiform cartilage. All bleeding was stopped and the peritoneum was opened to the extent of about one inch. The tumour presented itself at the wound, could be moved freely, and had formed no adhesions. It was found to have occupied the liver. Some of the contents, which were of the usual hydatid character, were removed by aspriration. An incision, about three-quarters of an inch, was then made into the cyst and the finger introduced for the dual purpose of preventing leakage into the abdomen and of introducing the cyst wall into the abdominal wound. One hundred and twenty ounces of fluid then escaped, and even then the cavity was not emptied. The incision into the cyst was then enlarged and attached to the abdominal

${ }_{3}$ Dr. Ray-Pailhade, from experiments on the action of sulphur in ${ }^{3} \mathrm{Dr}$. Ray Pailhade, from experiments on the action of sulphur in
yeast which he calls yhilotbion, which can combine vith sulphur. Particulars as to his experiments will be found in his Pushe:-3hes Expérimentale sur le Philothior. parieties by a double set of sutures, the inner set being composed of a continuous stitch and serving to fix the hepatic incision to the parietal peritoneum. By the guidance of the finger placed within the cyst a few outside interrupted sutures were so placed as not to perforate the whole thickness of the cyst wall, these serving both to lessen the drag upon the abdominal wound and to extend the area of opposed peritoneum. The stitching being completed large portions of the cyst wall were removed by forceps, and the cavity well washed out by quantities of mild warm boracic lotion. A large-sized drainage-tube was inserted and the wound was dressed in the usual way. With the exception of an occasional elevation of temperature the subsequent progress of the case was in every way satisfactory. The cavity was regularly washed out, and for some four or five months continued to discharge, and for the first six weeks portions of the cyst wall were found in the dressings.

On Sept. 2nd the patient was discharged, cured.

Liverpool.

\section{d attirtror}

\section{HOSPITAL PRACTICE, BRITISH AND FOREIGN.}

Nulla autem est alia pro certo noscendi via, nisi quamplurimas et mor. borum et dissectionum historias, tum aliorum tum proprias collectas habere, et inter se comparare. - MergagNI De Sed. et Cons. Morb., habere, et inter
lib. iv. Procmium.

\section{LONDON HOSPITAT.}

\section{A CASE OF LOCALISED SUPPURATIVE PERITONITIS WITH} GASEOUS DECOMPOSITION.

(Under the care of Mr. MCCARTHY.)

THIs is an example of an acute form of abdominal abscess to which the term "tympanitic" is sometimes applied. The operation did not throw any light on the causation of the disease, and that must remain obscure, especially as the vermiform appendix could not be felt. We occasionally meet with somewhat similar cases in younger people in which the appendix is also probably the cause of the trouble, but which close satisfactorily, and nothing further occurs to help in the diagnosis. The other cases mentioned by Mr. MacCarthy render the series of considerable interest.

In December, 1893, Mr. McCarthy was requested to see a man who had been admitted on the medical side of the London Hospital three days previously with abdominal trouble. The patient, a man aged thirty-two, with an excellent family and personal history, had been suddenly seized with severe abdominal pain followed by vomiting. For this he was admitted into the hospital. His bowels acted with purgatives and enemata, but the pain and romiting persisted. The romited matters consisted of food and bilestained fluid. His temperature was normal. When seen by Mr. McCarthy he was in great pain and writhed about in bed, so as to render examination difficult. When he was induced to lie still for a few seconds the appearance of the abdomen was remarkable. Above the umbilicus the abdomen was slightly retracted, and below the umbilicus it was distended, especially in the centre, which from the umbilicus to the symphysis pubis presented an ovoid prominence, such as would be caused by a greatly distended bladder. Percussion was impossible, as the slightest touch caused great pain, but the appearance and history of the patient suggested localised suppuration, with gaseous decomposition. The patient having assented to an operation if it should be thought requisite was anæsthetised. The percussion note over the central prominence was then found to be very tympanitic. A catheter was passed but the bladder was empty. The abdomen having been shaved and washed with carbolic lotion ( 1 in 20) a vertical incision for about two inches was made through the skin in the middle line midway between the umbilicus and symphysis pubis. This was carried down layer by layer until the peritoneum was exposed. When this was punctured a quantity of fetid gas escaped. When the opening was enlarged about a pint of putrid pus 